\section{OPEN ACCESS}

Edited by:

Roberta Marra

University of Naples Federico II, Italy

Reviewed by:

Umut Toprak

Ankara University, Turkey

Andrea Battisti,

University of Padua, Italy

*Correspondence:

Gianluca Tettamant

gianluca.tettamanti@uninsubria.it

Flavia Marinelli

flavia.marinelli@uninsubria.it

${ }^{t}$ These authors have contributed equally to this work

Specialty section:

This article was submitted to

Microbial Symbioses,

a section of the journal

Frontiers in Microbiology

Received: 07 April 2019

Accepted: 31 May 2019

Published: 18 June 2019

Citation:

Berini F, Casartelli M, Montali A, Reguzzoni M, Tettamanti G and

Marinelli $F$ (2019)

Metagenome-Sourced Microbial

Chitinases as Potential Insecticide

Proteins. Front. Microbiol. 10:1358.

doi: 10.3389/fmicb.2019.01358

\title{
Metagenome-Sourced Microbial Chitinases as Potential Insecticide Proteins
}

\section{Francesca Berini ${ }^{1+}$, Morena Casartelli2t, Aurora Montali ${ }^{3}$, Marcella Reguzzoni ${ }^{4}$, Gianluca Tettamanti ${ }^{3 *}$ and Flavia Marinelli ${ }^{*}$}

1 Laboratory of Microbial Biotechnology, Department of Biotechnology and Life Sciences, University of Insubria, Varese, Italy, ${ }^{2}$ Laboratory of Insect Physiology and Biotechnology, Department of Biosciences, University of Milan, Milan, Italy,

${ }^{3}$ Laboratory of Invertebrate Biology, Department of Biotechnology and Life Sciences, University of Insubria, Varese, Italy,

${ }^{4}$ Laboratory of Human Morphology, Department of Medicine and Surgery, University of Insubria, Varese, Italy

Microbial chitinases are gaining interest as promising candidates for controlling plant pests. These enzymes can be used directly as biocontrol agents as well as in combination with chemical pesticides or other biopesticides, reducing their environmental impact and/or enhancing their efficacy. Chitinolytic enzymes can target two different structures in insects: the cuticle and the peritrophic matrix (PM). PM, formed by chitin fibrils connected to glycoproteins and proteoglycans, represents a physical barrier that plays an essential role in midgut physiology and insect digestion, and protects the absorptive midgut epithelium from food abrasion or pathogen infections. In this paper, we investigate how two recently discovered metagenomesourced chitinases (Chi18H8 and 53D1) affect, in vitro and in vivo, the PM integrity of Bombyx mori, a model system among Lepidoptera. The two chitinases were produced in Escherichia coli or, alternatively, in the unconventional - but more environmentally acceptable - Streptomyces coelicolor. Although both the proteins dramatically altered the structure of $B$. mori PM in vitro, when administered orally only 53D1 caused adverse and marked effects on larval growth and development, inducing mortality and reducing pupal weight. These in vivo results demonstrate that 53D1 is a promising candidate as insecticide protein.

Keywords: insecticidal proteins, chitinase, metagenomics, heterologous expression, Streptomyces, insect control, Bombyx mori, peritrophic matrix

\section{INTRODUCTION}

Pesticides derived from chemical synthesis are massively used to control different pests that constantly threaten crop production (Atwood and Paisley-Jones, 2017). The main drawbacks of chemically synthesized pesticides are their broad toxicity and accumulation into ecosystems and food chains (Kumar et al., 2019). Alternatively, biocontrol or biological control, i.e., the use of organisms or their products (biopesticides), is favored by the better selectivity of these agents toward the target pests, their biodegradability, and reduced toxicity (Czaja et al., 2015; Bonanomi et al., 2018; Damalas and Koutroubas, 2018). In contrast, the successful use of biocontrol agents is often limited by their instability and scarce persistence into environment, as well as by their slower mode of action and reduced efficacy in comparison to chemical pesticides. Bacteria and fungi exhibiting 
fungicidal, insecticidal, and/or nematicidal action are commonly used as biocontrol agents. They produce antibiotics and secrete a variety of hydrolytic enzymes (chitinases, proteases, lipases, and glucanases), which concur in disrupting essential structures for pathogen life. A compelling alternative is formulating cocktails of (semi)purified antibiotics and enzymes, which mimic living biocontrol agents, without presenting the limitations inherent to their use and storage. Such biopesticides can be used alone or in combination with other controlling agents to enhance their efficacy (Regev et al., 1996; Karasuda et al., 2003; Liu et al., 2010). If added to chemically synthesized pesticides, biopesticides might allow the reduction of their dosage, alleviating their negative impact on the ecosystem (Karasuda et al., 2003). To this purpose, chitinases represent promising biopesticides, since they hydrolyze chitin, which is present in different plant pests, i.e., insects, fungi, and nematodes (Mavromatis et al., 2003; Neeraja et al., 2010; Hjort et al., 2014; Soares et al., 2015; Berini et al., 2016, 2017b, 2018). Additionally, they are harmless for plants and vertebrates, which do not possess chitin in their tissues. Chitin is a linear homopolymer of $\mathrm{N}$-acetylglucosamine (GlcNAc) and exerts fundamental roles in the vital structures of pests. It is a structural component of cell wall in fungi, of eggshell in nematodes, and of both cuticle and peritrophic matrix (PM) in insects. PM is a thin acellular sheath formed by chitin, glycoproteins, and proteoglycans, which lines the midgut epithelium of most insects (Hegedus et al., 2009; Berini et al., 2018). Chitinases belong to the family of glycosyl hydrolases. Based on their mode of action on chitin, they are classified as endochitinases, which split chitin randomly at internal sites, or as exochitinases that remove monomers $(\beta-N$-acetyl glucosaminidases) or dimers (chitobiosidases) of GlcNAc from the non-reducing end of chitin chains (Adrangi and Faramarzi, 2013; Berini et al., 2018).

In the recent years, we applied function- and/or sequencebased screening approaches to different metagenomes for discovering novel bioactive chitinases of microbial source, which differ from those already known that have been discovered by classical microbiological methods (Hjort et al., 2014; Cretoiu et al., 2015; Berini et al., 2017b). Since the vast majority of microorganisms present in natural samples (up to 9999.9\%) are recalcitrant to cultivation, metagenomics, being culture-independent, facilitates the task of encrypting novel chitinases (Berini et al., 2017a). Thanks to this approach, two of the first metagenomics-sourced chitinases were recently discovered: Chi18H8 was identified in 2014 from a naturally phytopathogen-suppressive soil in Sweden (Hjort et al., 2014; Berini et al., 2017b), whereas 53D1 was identified in 2015 in a chitin-supplemented agricultural soil from an experimental farm in the Netherlands (Cretoiu et al., 2015). Few milligrams of both chitinases were initially produced in Escherichia coli as heterologous host and partially biochemically/functionally characterized. Interestingly, Chi18H8 showed antifungal activity toward the phytopathogen fungi Fusarium graminearum and Rhizoctonia solani (Hjort et al., 2014; Berini et al., 2017b), whereas 53D1 looked interesting since it was markedly stable in a wide range of conditions, including in the presence of high salt concentrations (Cretoiu et al., 2015). We recently described the development to a $30-\mathrm{L}$ bioreactor pilot scale of an effective process to produce Chi18H8 by mild solubilization of inclusion bodies (IBs) in E. coli (Berini et al., 2017b). Herein, we describe the optimization of 53D1 production by using an alternative heterologous host - the Gram-positive bacterium Streptomyces coelicolor A3(2) - and report on producing and testing both Chi18H8 and 53D1 as insecticidal proteins in Bombyx mori, a reference model among Lepidoptera. To our knowledge, this is the first investigation on the insecticidal activity of metagenomesourced chitinases, which might represent promising candidates as biocontrol agents.

\section{MATERIALS AND METHODS}

\section{D1 Gene Cloning}

The nucleotide sequence of the metagenomic fosmid insert that includes 53D1 chitinase gene was deposited in the GenBank database (accession number LN824156.1) (Cretoiu et al., 2015). The chitinase-encoding cDNA was sub-cloned into the multicopy expression vector pIJ86 (Binda et al., 2013) (kindly gifted by M. J. Bibb, John Innes Centre, Norwich, United Kingdom) under the control of the constitutive $e r m E^{*}$ promoter, by using the fosmid DNA as template. Primers used for amplification were pIJ86_53D1_FW (5' ATATGGATCCGTATGAAGGAGGTCA TTCATGAGTCACGGTTCGGTC 3') and pIJ86_53D1_RV (5' ATTAAAGCTTCTAGTGGTGGTGGTGGTGGTGCGGTCTCA GCCGGGA $3^{\prime}$ ), including the restriction sites (underlined) for BamHI and HindIII, respectively, and introducing a C-terminal $\mathrm{His}_{6}$-Tag in the recombinant protein. All cloning procedures were carried out in E. coli DH5 $\alpha$ (Invitrogen-Life Technology, Carlsbad, CA, United States). The construct was checked by DNA sequencing (BMR Genomics, Padua, Italy) and transformed into the non-methylating E. coli ET12567/pUZ8002 cells (Marcone et al., 2010b). Luria-Bertani (LB, Sigma-Aldrich, St. Louis, MO, United States) agar plates were used for propagating E. coli strains.

Intergeneric conjugation between the E. coli donor and the recipients S. coelicolor A3(2), S. venezuelae ATCC 10595, and S. lividans TK24 was conducted following the protocol reported in Binda et al. (2013). Transformation of the recombinant Streptomyces spp. was checked by colony PCR (Binda et al., 2013).pIJ86_53D1_FW and pIJ86_53D1_RV primers were used to verify ex-conjugants carrying pIJ86::53D1 plasmid. Primers pIJ86_FW (5' TGCACGCGGTCGATCTTGAC 3') and pIJ86_RV (5' TCATGGTCGGTCTCCTGGTG $3^{\prime}$ ), annealing to regions of the vector around the multiple cloning site, were used to check transformation with the empty pIJ86 vector.

\section{D1 Heterologous Production}

Reagents were purchased from Sigma-Aldrich, St. Louis, MO, United States, unless otherwise indicated. Mannitol soya flour (MS) agar medium (Kieser et al., 2000) was used for propagating Streptomyces spp. Streptomycetes were stored for long-term preservation as spores in $10 \%(\mathrm{v} / \mathrm{v})$ glycerol. For cultivating the recombinant strains, agar plates and liquid media were always supplemented with $50 \mu \mathrm{g} / \mathrm{mL}$ apramycin. Strains were 
reactivated by growing them for $72 \mathrm{~h}$ into $100-\mathrm{mL}$ Erlenmeyer flasks containing $20 \mathrm{~mL}$ AurM medium (in g/L: 20 maltose, 10 dextrin, 15 soybean meal, 4 casein enzymatic hydrolysate, 4 bacteriological peptone, 2 yeast extract, $2 \mathrm{CaCO}_{3}, \mathrm{pH}$ 7.0) (Marcone et al., 2010b). Three hundred milliliters baffled flasks containing $50 \mathrm{~mL}$ YEME (yeast extract - malt extract, in $\mathrm{g} / \mathrm{L}$ : 3 yeast extract, 5 bacteriological peptone, 3 malt extract, 20 glucose, pH 7.0) (Binda et al., 2013) were then inoculated at $10 \%(\mathrm{v} / \mathrm{v})$ and further shaken at 200 revolutions per minute $(\mathrm{rpm})$ at $28^{\circ} \mathrm{C}$ for $72 \mathrm{~h}$. Finally, 500-mL baffled flasks containing $100 \mathrm{~mL}$ of five different production media (commonly used for streptomycetes) were inoculated at $10 \%(\mathrm{v} / \mathrm{v})$, incubated at $200 \mathrm{rpm}$ and $28^{\circ} \mathrm{C}$ for $240 \mathrm{~h}$. Liquid production media used were YEME, MV (medium V) (Marcone et al., 2010a), R5 medium (Kieser et al., 2000), TSB (tryptone soya broth) (Kieser et al., 2000), and Bennett's medium (Dalmastri et al., 2016). All media were supplemented with $20 \mathrm{~g} / \mathrm{L}$ glucose, if not already included, in order to repress the endogenous chitinolytic system of streptomycetes (Berini et al., 2018).

Every $24 \mathrm{~h}, 10 \mathrm{~mL}$ of culture broth were centrifuged at $1900 \times g$ for $10 \mathrm{~min}$ at $4^{\circ} \mathrm{C}$. Cell-free culture broths were collected and $\mathrm{pH}$ and residual glucose were measured by $\mathrm{pH}$ Test Strips 4.5-10.0 and Diastix strips (Bayer, Leverkusen, Germany). Secreted 53D1 production was estimated in cellfree culture broths by western blot analysis [after protein concentration by $10 \%(\mathrm{v} / \mathrm{v})$ trichloracetic acid precipitation] and fluorimetric enzyme activity assay (see below). In parallel, cell pellets were recovered and biomass production was measured as wet weight. Then, pellets were sonicated on ice with 10-15 cycles of $30 \mathrm{~s}$ each (interposed with 30s intervals), using a Branson Sonifier 250 (Dansbury, CT, United States) in $20 \mathrm{mM}$ sodium acetate $\mathrm{pH} 5.0$ supplemented with $10 \mu \mathrm{g} / \mathrm{mL}$ deoxyribonuclease (DNase) and $0.19 \mathrm{mg} / \mathrm{mL}$ phenylmethylsulfonylfluoride (PMSF). To remove insoluble material, centrifugation at $20,000 \times g$ for $40 \mathrm{~min}$ at $4^{\circ} \mathrm{C}$ followed. Production of intracellular 53D1 was checked in the soluble fractions by western blot analysis and fluorimetric enzyme activity assay (see below).

\section{D1 Purification}

For 53D1 purification, S. coelicolor/pIJ86::53D1 was grown for 192-240 h in YEME medium. Proteins secreted in the cell-free culture broth were precipitated by slowly adding $80 \%(\mathrm{w} / \mathrm{v})$ ammonium sulfate. After $2 \mathrm{~h}$ incubation at $4^{\circ} \mathrm{C}$, centrifugation at $12,000 \times g$ at $4^{\circ} \mathrm{C}$ for $40 \mathrm{~min}$ followed. The pellet was re-suspended in $1 / 5(\mathrm{v} / \mathrm{v})$ of $20 \mathrm{mM}$ Tris- $\mathrm{HCl} \mathrm{pH} 8.0$ and dialyzed against the same buffer. The recombinant protein was purified onto a $5-\mathrm{mL} \mathrm{Ni}^{2+}$-Hitrap chelating affinity column $(1.6 \mathrm{~cm} \times 2.5 \mathrm{~cm}$; GE Healthcare Sciences, Little Chalfont, United Kingdom), according to manufacturer's instructions. The column was equilibrated with $20 \mathrm{mM}$ Tris- $\mathrm{HCl} \mathrm{pH} \mathrm{8.0,500} \mathrm{mM}$ $\mathrm{NaCl}$, and $20 \mathrm{mM}$ imidazole. After extensive washing, the recombinant protein was eluted with $20 \mathrm{mM}$ Tris- $\mathrm{HCl} \mathrm{pH}$ 8.0, $500 \mathrm{mM} \mathrm{NaCl}$, and $250 \mathrm{mM}$ imidazole, followed by dialysis for $3 \mathrm{~h}$ against $20 \mathrm{mM}$ sodium acetate $\mathrm{pH}$ 5.0. The purified protein was finally concentrated with $30 \mathrm{~K}$ Amicon Ultra-2 centrifugal filter devices (Merck KGaA, Darmstadt, Germany).

\section{Chi18H8 Production and Purification}

Chi18H8 production in E. coli BL21 Star ${ }^{\mathrm{TM}}$ (DE3), carrying the pET24b(+)::chil8H8 expression plasmid, and its solubilization from IBs were accomplished as previously described (Berini et al., 2017b). In brief, to prepare the protein used in this work, E. coli BL21 Star ${ }^{\mathrm{TM}}$ (DE3)/pET24b(+)::chi18H8 cells were grown in $300-\mathrm{mL}$ baffled Erlenmeyer flasks containing $80 \mathrm{~mL}$ LB medium supplemented with $50 \mu \mathrm{g} / \mathrm{mL}$ kanamycin, incubated overnight at $37^{\circ} \mathrm{C}$ and $200 \mathrm{rpm}$. Two liters flasks with $750 \mathrm{~mL}$ selective LB medium were inoculated with the pre-cultures (initial $\mathrm{OD}_{600 \mathrm{~nm}}=0.1$ ), and incubated at $37^{\circ} \mathrm{C}$ and $200 \mathrm{rpm}$ until $\mathrm{OD}_{600 \mathrm{~nm}}$ reached 0.6. Protein production was induced by adding $0.4 \mathrm{mM}$ isopropyl $\beta$-D-1-thiogalactopyranoside (IPTG) and cultivation was prolonged at $20^{\circ} \mathrm{C}$ for further $24 \mathrm{~h}$.

Cells were harvested by centrifugation and re-suspended in $50 \mathrm{mM}$ Tris- $\mathrm{HCl} \mathrm{pH} \mathrm{8.0,25 \% (w/v)} \mathrm{sucrose,} \mathrm{and} 1 \mathrm{mM}$ ethylenediaminetetraacetic acid (EDTA). After incubation for $30 \mathrm{~min}$ at room temperature and vigorous shaking, samples were sonicated (six cycles of $30 \mathrm{~s}$ each). A total of $0.2 \mathrm{M} \mathrm{NaCl}, 1 \%$ $(\mathrm{w} / \mathrm{v})$ sodium deoxycholate (DOC), and $1 \%(\mathrm{v} / \mathrm{v})$ Nonidet P-40 were added; the samples were further incubated as above and centrifuged $\left(20,000 \times g\right.$ at $4^{\circ} \mathrm{C}$ for $\left.30 \mathrm{~min}\right)$. The pellet was washed with $1 \%(\mathrm{v} / \mathrm{v})$ Triton X-100 and $1 \mathrm{mM}$ EDTA and centrifuged $\left(12,000 \times g\right.$ at $4^{\circ} \mathrm{C}$ for $\left.10 \mathrm{~min}\right)$. IB washing with this buffer was repeated twice, followed by washing with deionized water. After overnight storage at $-20^{\circ} \mathrm{C}$, the frozen pellet was resuspended in $10 \mathrm{mM}$ lactic acid $(10 \mathrm{~mL} / \mathrm{g}$ cell $)$ and incubated at $37^{\circ} \mathrm{C}$ and $200 \mathrm{rpm}$ for $5 \mathrm{~h}$. Centrifugation at $1900 \times g$ at $4^{\circ} \mathrm{C}$ for 5 min was employed for removing insoluble material. Finally, solubilized Chi18H8 was dialyzed overnight against $20 \mathrm{mM}$ sodium acetate $\mathrm{pH}$ 5.0.

\section{SDS-PAGE Electrophoresis and Western Blot}

Protein fractions were analyzed by sodium dodecyl sulfate polyacrylamide $(12 \% \mathrm{w} / \mathrm{v})$ gel electrophoresis (SDS-PAGE), using a Tris-glycine system and Coomassie brilliant blue R250 straining. For western blot analysis, anti His-Tag Antibody HRP conjugate (Novagen Inc., Madison, WI, United States) and chemiluminescence (ECL Western Blotting Detection System, GE Healthcare Sciences, Little Chalfont, United Kingdom) were used for protein identification.

\section{Chitinase Activity Assays}

Chitinase activities were assayed by using the fluorimetric chitooligosaccharide analogs 4-methylumbelliferyl $\mathrm{N}$-acetyl$\beta$-D-glucosaminide (4-MU-GlcNAc), 4-methylumbelliferyl $N, N^{\prime}$-diacetyl- $\beta$-D-chitobioside $\quad\left[4-\mathrm{MU}-(\mathrm{GlcNAc})_{2}\right], \quad$ and 4-methylumbelliferyl $\quad N, N^{\prime}, N^{\prime \prime}$-triacetyl- $\beta$-D-chitotrioside [4-MU-(GlcNAc) 3 ] (Cretoiu et al., 2015). Activity on these synthetic compounds was assayed in $100 \mathrm{mM}$ sodium acetate $\mathrm{pH} 5.0$, at $37^{\circ} \mathrm{C}$. Chitinolytic activity was also determined on colloidal chitin as described in Berini et al. (2016). In this case, activity was measured at $\mathrm{pH} 3.0,5.0,7.0$, or 9.0 , by adjusting colloidal chitin's $\mathrm{pH}$ with $0.1 \mathrm{M} \mathrm{NaOH}$. One unit (U) of chitinase activity was defined as the amount of enzyme required for the 
release of $1 \mu \mathrm{mol}$ of $4-\mathrm{MU}$ or of GlcNAc per min at $37^{\circ} \mathrm{C}$. The control of protease or lipase activities in purified 53D1 and $\mathrm{Chi} 18 \mathrm{H} 8$ preparations was conducted as described in Berini et al. (2016).

\section{Experimental Insects}

Larvae of B. mori [polyhybrid strain $(126 \times 57)(70 \times 90)$ ] were provided by CREA - Honeybee and Silkworm Research Unit (Padua, Italy). Insects were reared on artificial diet (Cappellozza et al., 2005) at $25 \pm 0.5^{\circ} \mathrm{C}$, under a 12:12 light-dark photoperiod, with $70 \pm 5 \%$ relative humidity. Once insects had reached the last larval instar, they were staged and synchronized (see Franzetti et al., 2012 for details).

\section{Ultrastructural Analysis of the PM Isolation of the PM and in vitro Incubation With Chi18H8 or 53D1 Chitinases}

On second day of the fifth instar, larvae were anaesthetized with $\mathrm{CO}_{2}$. Midgut was isolated by cutting the insect dorsally and the PM was carefully separated from the midgut epithelium. The lumen content was removed from the PM by rinsing the matrix with PBS (phosphate-buffered saline, $137 \mathrm{mM} \mathrm{NaCl}$, $2.7 \mathrm{mM} \mathrm{KCl}, 4.3 \mathrm{mM} \mathrm{Na} \mathrm{HPO}_{4}, 1.4 \mathrm{mM} \mathrm{KH} \mathrm{PO}_{4}, \mathrm{pH} 7.0$ ). Each sample was divided into four pieces and transferred into a 24-multiwell plate: two pieces were treated with Chi18H8 or $53 \mathrm{D} 1$ ( $40.5 \mathrm{U}_{\text {tot }}$ per well, calculated as the sum of chitobiosidase and endochitinase activities on 4-MU-(GlcNAc) 2 and 4-MU(GlcNAc) $)_{3}$, respectively, in $100 \mathrm{mM}$ sodium acetate buffer $\mathrm{pH}$ 5.0, while the other two were incubated in the same buffer in the absence of chitinases (controls). All the samples were processed for electron microscopy analysis.

\section{Scanning Electron Microscopy (SEM)}

After incubation with 53D1 or Chi18H8, PM was fixed with $4 \%(\mathrm{v} / \mathrm{v})$ glutaraldehyde in $0.1 \mathrm{M}$ sodium cacodylate buffer $\mathrm{pH}$ 7.4 , overnight at $4^{\circ} \mathrm{C}$. After post-fixation with $1 \%(\mathrm{w} / \mathrm{v})$ osmium tetroxide and $1.25 \%(\mathrm{w} / \mathrm{v})$ potassium ferrocyanide for $1 \mathrm{~h}$, samples were dehydrated in an ethanol series and then incubated in hexamethyldisilazane (two steps of $10 \mathrm{~min}$ each). Samples were mounted on stubs, carbon coated with a Sputter K250 coater, and finally observed with a SEM-FEG XL-30 microscope (Philips, Eindhoven, Netherlands).

\section{Transmission Electron Microscopy (TEM)}

To analyze the samples at TEM, PM was fixed with $4 \%$ (v/v) glutaraldehyde in $0.1 \mathrm{M}$ sodium cacodylate buffer $\mathrm{pH}$ 7.4 , overnight at $4^{\circ} \mathrm{C}$ and then post-fixed with $1 \%(\mathrm{w} / \mathrm{v})$ osmium tetroxide for $1 \mathrm{~h}$. After dehydration in an ethanol series, specimens were embedded in an Epon/Araldite 812 mixture. Ultra-thin sections were obtained with Leica Reichert Ultracut S (Leica, Nußloch, Germany), then stained with lead citrate and uranyl acetate, and finally observed with a JEM1010 transmission electron microscope (Jeol, Tokyo, Japan). Images were acquired with a Morada digital camera (Olympus, Münster, Germany).

\section{Bioassays With Chi18H8 and 53D1 Chitinases}

After hatching, larvae were reared as reported in the Section "Experimental Insects," and fed ad libitum with small pieces of artificial diet $(1 \mathrm{~cm} \times 1 \mathrm{~cm} \times 1 \mathrm{~mm})$, each overlaid with an equal volume $(65 \mu \mathrm{L})$ of Chi18H8 or $53 \mathrm{D} 1\left(6 \mathrm{U}_{\text {tot }} / \mathrm{cm}^{2}\right.$ diet $)$ dissolved in $100 \mathrm{mM}$ sodium acetate, $\mathrm{pH}$ 5.0. Control larvae were grown on small pieces of artificial diet overlaid with the same volume of sodium acetate buffer. The diet was replaced every day. Different parameters were recorded: larval mortality (reported as percentage of the initial number of larvae), length of the larval stage (from hatching to the occurrence of wandering behavior), and weight of the pupae (evaluated on the eighth day of the pupal stage). For bioassays with 53D1, maximal larval weight before pupation and cocoon weight (measured on the eighth day of the pupal stage) were registered, too. Developmental stages of B. mori were defined according to Franzetti et al. (2012). Bioassays were performed in triplicate, by using at least 11 larvae for each experimental group. PM samples from larvae at the second day of the fifth instar reared on diet overlaid with 53D1 and relative controls were collected and processed for the analysis at SEM and TEM, as reported in the Section "Ultrastructural Analysis of the PM."

\section{In vitro Incubation of Chitinases With Midgut Juice}

Midgut juice was extracted from larvae at the second day of the fifth instar. Insects were anaesthetized with $\mathrm{CO}_{2}$, whole midguts were dissected and their luminal content was collected into a centrifuge tube. Centrifugation at $15,000 \times g$ for $10 \mathrm{~min}$ was performed to remove insoluble material. Supernatants were aliquoted, stored at $-80^{\circ} \mathrm{C}$, and used within 2 weeks. Six $\mathrm{U}_{\text {tot }}$ of Chi18 8 8 or 53D1 were incubated at $25^{\circ} \mathrm{C}$ in $100 \mathrm{mM}$ Tris- $\mathrm{HCl}$ $\mathrm{pH} 8.0$ (control) or in the presence of different dilutions of the midgut juice (undiluted, or diluted 1:10 or 1:100 in $100 \mathrm{mM}$ Tris$\mathrm{HCl} \mathrm{pH} \mathrm{8.0).} \mathrm{Aliquots} \mathrm{were} \mathrm{withdrawn} \mathrm{at} \mathrm{regular} \mathrm{intervals} \mathrm{up} \mathrm{to}$ $8 \mathrm{~h}$ and the residual chitobiosidase activity was measured using 4$\mathrm{MU}-(\mathrm{GlcNAc})_{2}$ as substrate, according to the standard protocol described in the Section "Chitinase Activity Assays."

\section{RESULTS}

\section{Production and Characterization of Chi18H8}

Chi18H8 is a protein of 424 amino acids with a predicted molecular mass of $45.96 \mathrm{kDa}$ and a theoretical isoelectric point of 7.75. To assay its insecticidal activity, Chi18H8 was produced in 2-L flasks and recovered from E. coli BL21 Star ${ }^{\mathrm{TM}}$ (DE3)/pET24b(+)::chi18H8 cells (Table 1) by using a newly developed process based on the mild solubilization of IBs, as recently described in Berini et al. (2017b). Following purification, Chi18H8 migrated in SDS-PAGE gels as a single band of ca. $47 \mathrm{kDa}(46.77 \mathrm{kDa}$ is the expected molecular mass for the recombinant $\mathrm{His}_{6}$-tagged protein). Protein purity was estimated to be $>85 \%$ (Figure 1 ). 
TABLE 1 | Purification of Chi18H8 (A) from E. coli BL21 StarTM (DE3)/pET24b(+)::chi18H8 IBs and 53D1 (B) from S. coelicolor/plJ86::53D1 culture broth.

\begin{tabular}{|c|c|c|c|c|c|c|}
\hline Purification step & Volume (mL) & Total proteins (mg) & Total activity (U) & $\begin{array}{l}\text { Specific activity } \\
\text { (U/mg protein) }\end{array}$ & Purification (-fold) & Yield (\%) \\
\hline \multicolumn{7}{|l|}{$(A)$} \\
\hline IBs & 10.6 & 123.0 & 33.4 & 0.27 & 1.0 & 100.0 \\
\hline Soluble fraction from IBs & 53.0 & 71.8 & 2623.0 & 36.7 & 78.5 & 84.0 \\
\hline \multicolumn{7}{|l|}{ (B) } \\
\hline Crude broth & 1000.0 & 1125.0 & 1080.0 & 0.96 & 1.0 & 100.0 \\
\hline Ammonium sulfate precipitation & 200.0 & 1090.0 & 1067.1 & 0.98 & 1.0 & 98.8 \\
\hline Affinity chromatography & 114.1 & 34.9 & 956.6 & 27.4 & 28.5 & 88.5 \\
\hline
\end{tabular}

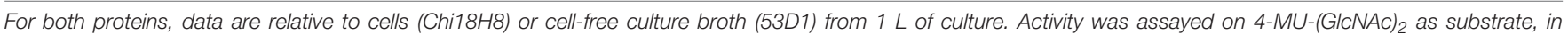
$100 \mathrm{mM}$ sodium acetate $\mathrm{pH}$ 5.0.

Fluorimetric enzyme assay using standard synthetic oligosaccharides confirmed the Chi18H8 prevalent chitobiosidase activity on 4-MU-(GlcNAc) 2 (37.92 $\pm 1.17 \mathrm{U} / \mathrm{mg}$ protein), its weaker endochitinase activity on $4-\mathrm{MU}-(\mathrm{GlcNAc})_{3}$ $(8.91 \pm 1.72 \mathrm{U} / \mathrm{mg}$ protein), and none $\beta$ - $N$-acetylglucosaminidase activity on 4-MU-GlcNAc. As reported in Table 2, pure Chi18H8 was able to hydrolyze colloidal chitin - a substrate that, although soluble, resembles the chemical structure of the naturally occurring insoluble chitin - with a maximum activity of about $1.47 \pm 0.25 \mathrm{U} / \mathrm{mg}$ protein at $\mathrm{pH}$ 5.0. At $\mathrm{pH}$ $3.0,7.0$, and 9.0 , ca. 22,83 , and $72 \%$ of the maximum activity were maintained, respectively (Table 2 ). None protease or lipase activity (lipases and proteases are enzymes usually secreted by streptomycetes that could interfere with the following insecticide assays) was detected in the enzyme preparation (data not shown).

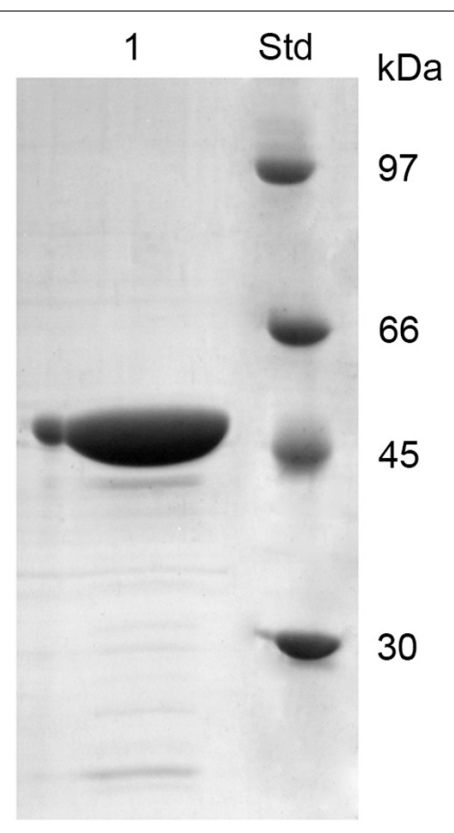

FIGURE 1 | SDS-PAGE of Chi18H8 solubilization from E. coli BL21 StarTM (DE3)/pET24b(+)::chi18H8 IBs. 1, solubilized Chi18H8; Std, standard reference proteins.

\section{Heterologous Expression of 53D1 in Streptomyces spp.}

$53 \mathrm{D} 1$ gene $(63.03 \% \mathrm{G}+\mathrm{C})$ consists of 1191 nucleotides coding for a protein of 396 amino acids with a predicted molecular mass of $43.60 \mathrm{kDa}$ and a theoretical isoelectric point of 4.83 . When cloned and expressed in E. coli, $>80 \%$ of the recombinant protein accumulated as inactive form in insoluble fractions. Despite many efforts, we could not develop a protocol for solubilizing 53D1 in a biologically active form from IBs, as we did for Chi18H8. In addition, as reported in Cretoiu et al. (2015), the recovery yield of the soluble active form of 53D1 from E. coli cytoplasmic fraction was too low (no more than $0.60 \mathrm{mg} / \mathrm{L}$ culture and $0.12 \mathrm{mg} / \mathrm{g}$ cell) to support its further trials as insecticide protein. Thus, in this paper we report an alternative expression platform using soil Gram-positive actinomycetes belonging to the genus Streptomyces as heterologous hosts for 53D1 production.

53D1 coding gene was thus cloned into the multicopy plasmid pIJ86 and introduced by intergeneric conjugation into S. lividans TK24, S. venezuelae ATCC 10595, and S. coelicolor A3(2). For selecting the best expression system, the three recombinant streptomycetes (and their control strains carrying empty vectors) were cultivated in five different media (see section "53D1 Heterologous Production"). Recombinant S. lividans/pIJ86::53D1 did not produce the heterologous chitinase -neither inside nor outside the cells - in any of the cultivation media used (data not shown). 53D1 was instead secreted by the recombinant $S$. venezuelae/pIJ86::53D1 growing in YEME medium (data not shown) and, to a major extent, by $S$. coelicolor/pIJ86::53D1 cultivated in the same condition (Figure 2). Western blot analysis indicated that S. venezuelae/pIJ86::53D1 produced a maximum of $8.75 \mathrm{mg} / \mathrm{L}$ of extracellular 53D1 (corresponding to $0.27 \mathrm{mg} / \mathrm{g}$ cell) (data

TABLE 2 | Chi18H8 and 53D1 activity on colloidal chitin at different pHs (mean \pm standard error from at least three independent experiments).

\begin{tabular}{ccc}
\hline pH & Chi18H8 (U/mg protein) & 53D1 (U/mg protein) \\
\hline 3.0 & $0.32 \pm 0.07$ & $2.75 \pm 0.35$ \\
5.0 & $1.47 \pm 0.25$ & $10.15 \pm 1.40$ \\
7.0 & $1.22 \pm 0.01$ & $7.10 \pm 0.20$ \\
9.0 & $1.06 \pm 0.04$ & $7.00 \pm 0.10$
\end{tabular}


not shown), whereas $S$. coelicolor/pIJ86::53D1 secreted up to $45 \mathrm{mg} / \mathrm{L}(0.83 \mathrm{mg} / \mathrm{g}$ cell) of 53D1 (Figure 2B). No traces of $53 \mathrm{D} 1$ were detected into cytoplasmic soluble fractions of both the recombinant strains (data not shown).

Comparison of S. coelicolor/pIJ86::53D1 (Figure 2B) growth curve with the one of its control strain carrying the empty vector (Figure 2A) indicated that S. coelicolor/pIJ86::53D1 grew faster and consumed glucose more efficiently. This better performance of $S$. coelicolor/pIJ86::53D1 was quite unexpected since the expression of heterologous genes usually causes a metabolic burden to the producing bacterial host, which slows down its growth rate (Binda et al., 2013). When observed at the optical microscope, the mycelium of $S$. coelicolor/pIJ86::53D1 was less clumpy than in the control strain; this phenotype might be due to a putative lysozyme-like activity of 53D1. It has been demonstrated that lysozyme, producing a more disperse mycelium, facilitates streptomycetes growth in liquid media
(Hobbs et al., 1989). A lysozyme activity of several chitinases was indeed previously reported by other authors (Bokma et al., 1997; Wohlkönig et al., 2010).

Cells of $S$. coelicolor/pIJ86::53D1 started to secrete 53D1 after approximately the first $24 \mathrm{~h}$ of growth and continued to produce the heterologous protein during the stationary growth phase: the maximum specific productivity was reached after $240 \mathrm{~h}$ (Figure 2B). Consistently, in the same period of time, the chitinase enzyme activity measured in cellfree culture broths of $S$. coelicolor/pIJ86::53D1 progressively increased and reached a maximum of ca. $18.5 \mathrm{U} / \mathrm{g}$ cell after $240 \mathrm{~h}$ (Figure 2D). As expected, no 53D1 was detectable by western blot analysis in the cell-free culture broths of S. coelicolor/pIJ86 (Figure 2A). The traces of chitinase activity detectable in the cell-free culture broths of the control strain (never exceeding the level $0.1 \mathrm{U} / \mathrm{g}$ cell; Figure 2C) were due to the endogenous streptomycetes chitinolytic system, opportunely
A

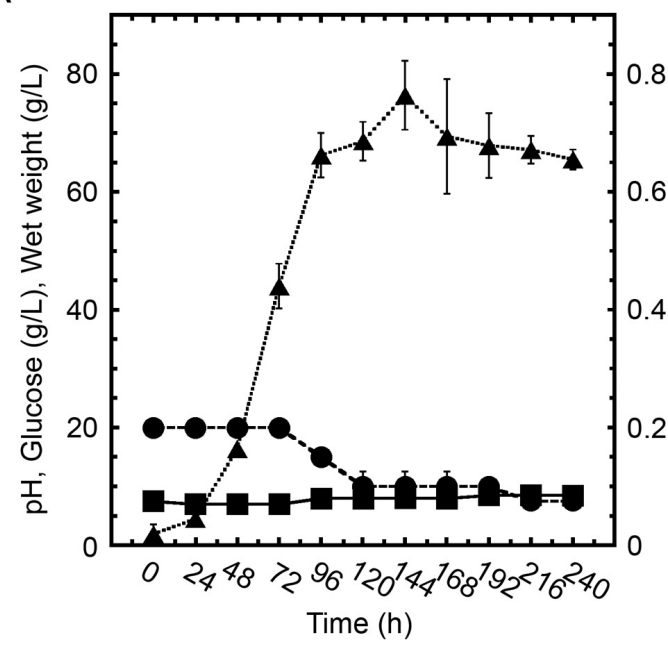

C

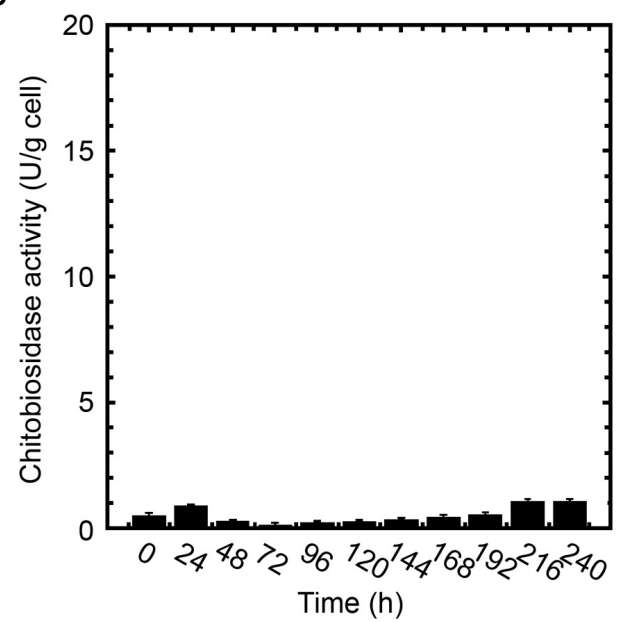

B

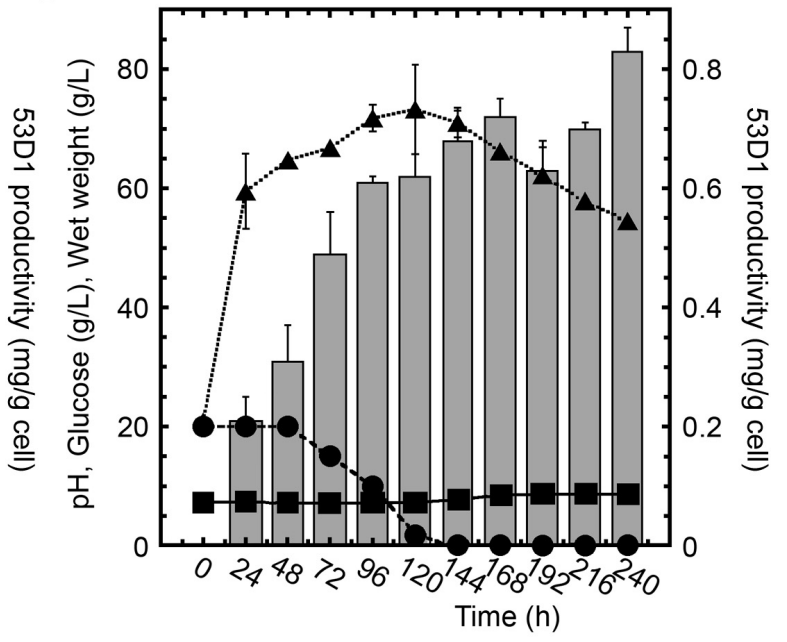

D

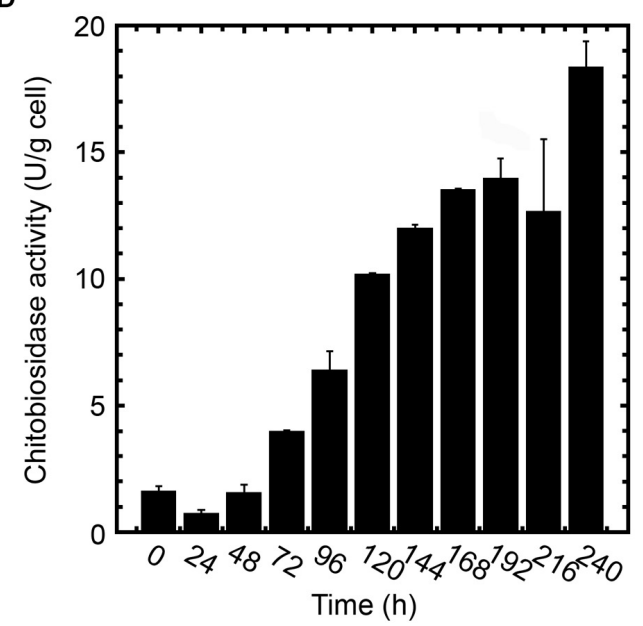

FIGURE 2 | Growth curves, 53D1 production (A,B), and chitinase activities (C,D) in S. coelicolor/plJ86 (left panels) and S. coelicolor/plJ86::53D1 (right panels),

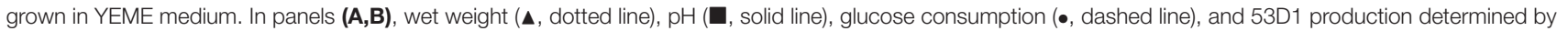
western blot analysis of cell-free culture broths (gray bars). In panels $\mathbf{( C , D )}$, chitinase activity of cell-free culture broths measured by fluorimetric activity assay on 4-MU-(GlcNAc) 2 as substrate (black bars). 
repressed by the addition of glucose to the cultivation medium (Berini et al., 2018).

\section{D1 Purification and Characterization}

53D1 was recovered from the culture broth of S. coelicolor/pIJ86::53D1, harvested after 192-240 h of growth in YEME medium, as described in the Sections "53D1 Heterologous Production" and "53D1 Purification." His6-53D1 was then purified as a single band of ca. $44 \mathrm{kDa}(44.40 \mathrm{kDa}$ is the expected molecular mass for the recombinant His $_{6}$-tagged protein) by means of HiTrap-chelating affinity chromatography, with a purity of ca. 90\% (Figure 3). Purification yield was $34.9 \mathrm{mg} / \mathrm{L}$ (Table 1), corresponding to ca. $0.64 \mathrm{mg} / \mathrm{g}$ cell. Fluorimetric enzyme assay using standard synthetic oligosaccharides confirmed that $53 \mathrm{D} 1$ has a prevalent chitobiosidase activity on $4-\mathrm{MU}-(\mathrm{GlcNAc})_{2}(31.60 \pm 2.90 \mathrm{U} / \mathrm{mg}$ protein), a weaker endochitinase activity on 4-MU-(GlcNAc) $)_{3}(16.42 \pm 1.85 \mathrm{U} / \mathrm{mg}$ protein), and none $\beta$ - $N$-acetyl-glucosaminidase activity on 4-MU-GlcNAc. On colloidal chitin, the maximum activity of 53D1 was measured at $\mathrm{pH} 5.0$, although the protein conserved ca. $70 \%$ of its maximum activity also at neutral and basic $\mathrm{pH}$. It conserved ca. $27 \%$ of its initial activity at pH 3.0 (Table 2). None protease or lipase activity was detected in the enzyme preparation (data not shown).

\section{In vitro Effects of 53D1 and Chi18H8 on the PM of $B$. mori Larvae}

To evaluate the potential insecticidal effects of 53D1 and Chi18H8, both chitinases were first tested in vitro by exposing

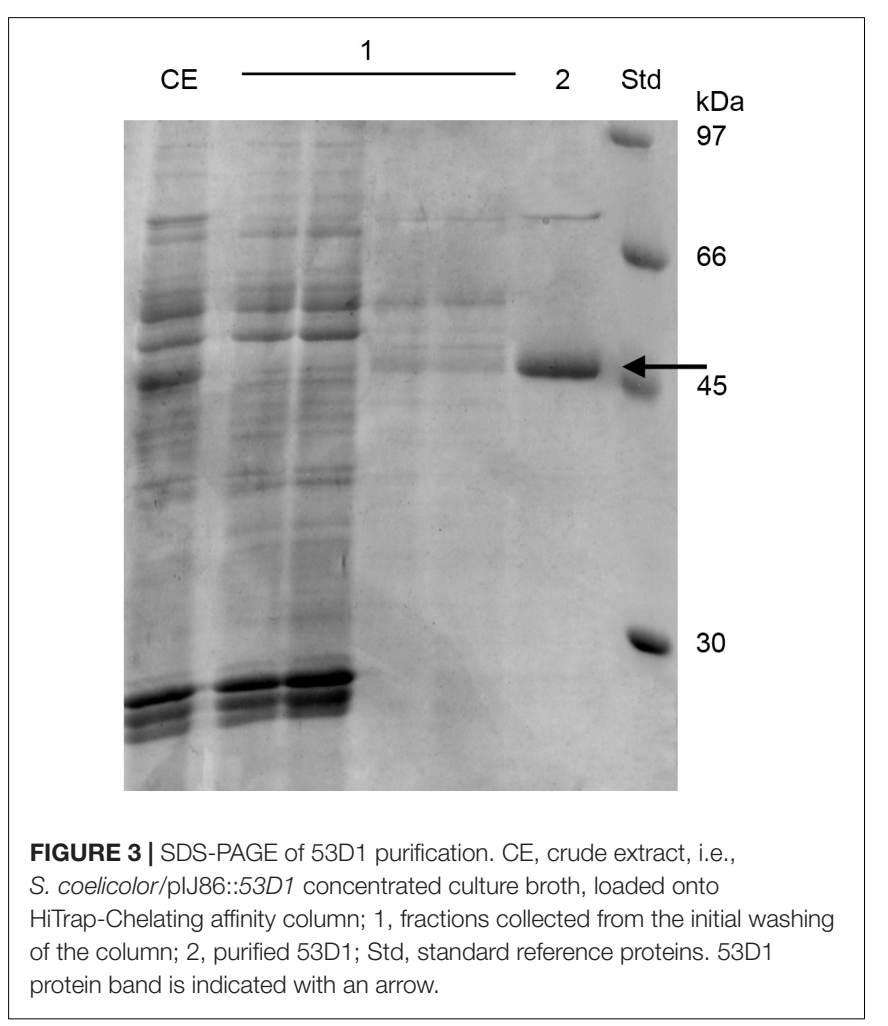

the PM isolated from last instar larvae to a concentrated preparation of pure enzymes $\left(40.5 \mathrm{U}_{\text {tot }}\right)$. SEM and TEM analyses of untreated PM (control) highlighted the well-organized and compact structure of B. mori PM: chitin fibrils were properly aligned and PM showed a continuous surface (Figures 4A,D). On the contrary, the analysis of the PM treated with Chi18H8 revealed a marked effect induced by the chitinase (Figures 4B,E). In particular, ruptures of the superficial layers (Figure 4B) and alteration of the integrity of the chitin network (Figures 4B,E) were clearly visible. The morphological analysis revealed a significant alteration of the structural organization of PM also when treated with 53D1 (Figures 4C,F). As for the PM treated with Chi18H8, the superficial layers of 53D1-treated PM were damaged (Figure 4C) and the disruption of the fibril network was visible (Figure $4 \mathrm{~F}$ ).

\section{In vivo Effects of 53D1 and Chi18H8 on B. mori Larvae}

To evaluate the in vivo effects of 53D1 and Chi18H8, bioassays exposing the larvae of $B$. mori to chitinase-containing diet were conducted. The larval mortality, the length of the larval stage, and the weight of the pupae were not significantly different between untreated (control) and Chi18H8-treated larvae (Table 3). In contrast, the developmental parameters recorded for larvae fed with 53D1-containing diet indicated a clear detrimental effect of the chitinase (Table 4). In fact, the mortality of 53D1-treated larvae was significantly higher than in control larvae, the duration of the larval stage of the survived larvae was $25 \%$ longer, and their maximal larval weight before pupation was markedly reduced. As shown in Figure 5, the effect on larval development was visible from early instars onward. Moreover, pupal and cocoon weight was significantly lower in 53D1-treated larvae than in controls (Table 4). Finally, the PM isolated from survived last instar larvae reared on 53D1 chitinase-containing diet showed a compromised structure both at SEM and TEM (Figure 6). These effects on PM caused by 53D1 were comparable to those previously observed in in vitro experiments (see Figure 4), indicating that the alterations of the larval growth and development observed in the bioassay were due to the direct effect of 53D1 chitinase on PM.

\section{D1 and Chi18H8 Residual Activity in B. mori Midgut Juice}

To explain the different in vivo activity of the two chitinases, the residual enzyme activity of Chi18H8 and 53D1 was measured following their incubation for different time intervals in the absence or presence of midgut juice (at different dilutions) isolated from B. mori larvae. Indeed, the midgut juice from lepidopteran larvae has an alkaline $\mathrm{pH}$ and contains enzymes responsible for macromolecule digestion, including proteases (Terra and Ferreira, 1994). 53D1 activity was stable in the control buffer at alkaline $\mathrm{pH} 8$ for at least $8 \mathrm{~h}$ (Figure 7A). In the presence of midgut juice, its residual activity was dependent on midgut juice dilution: anyhow, after $8 \mathrm{~h}$ of incubation with undiluted midgut juice the enzyme still retained ca. the $40 \%$ of its initial activity (Figure 7A). In contrast, the activity of Chi18H8 was much more drastically reduced by incubating the enzyme in the 

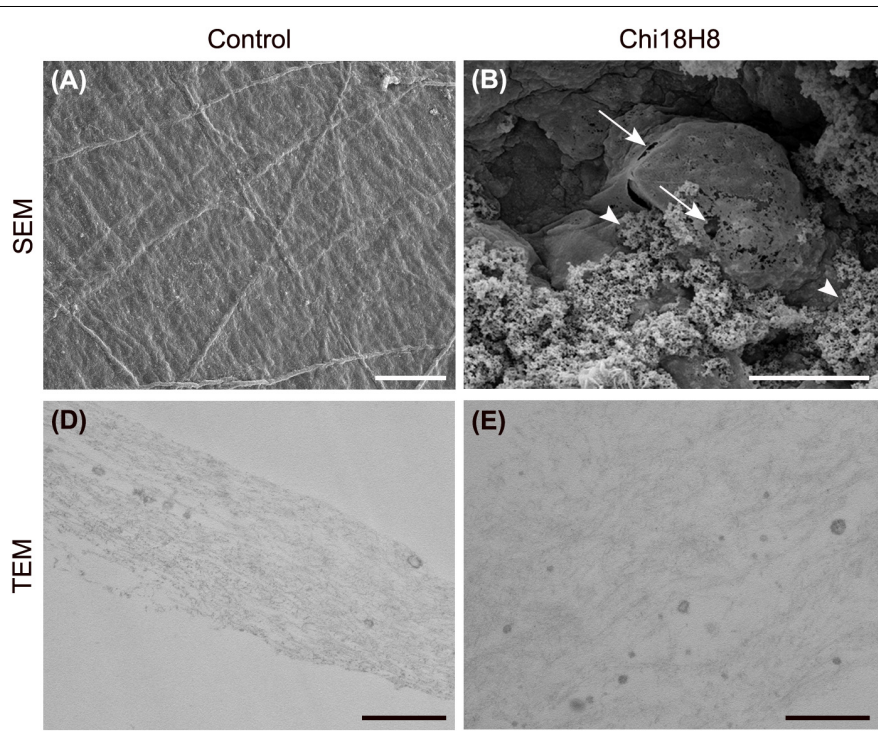

(E)

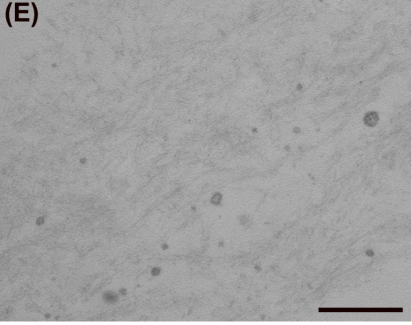

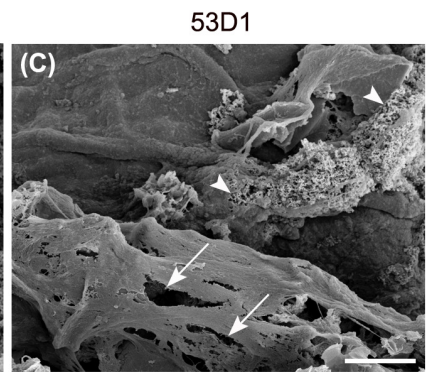

(F)

FIGURE 4 | Morphology of the peritrophic matrix treated with chitinases. SEM (A-C) and TEM (D-F). (A,D) Control samples; (B,E) in PM treated with Chi18H8, ruptures of the superficial layers (arrows) and alteration of the fibril network (arrowheads) are visible, as confirmed by TEM analysis; (C,F) similar effects can be observed in PM treated with 53D1. Bars: (A-C) $10 \mu \mathrm{m}$; (D-F) $0.5 \mu \mathrm{m}$.

control buffer at alkaline $\mathrm{pH}$ and in the presence of midgut juice (Figure 7B). After $8 \mathrm{~h}$ in the control buffer, the residual activity was reduced to less than $40 \%$. When incubated with 10 - and $100-$ fold diluted midgut juice, the residual activity after $8 \mathrm{~h}$ was ca. 3 and $23 \%$ of the initial activity, respectively. In the presence of undiluted midgut juice, Chi18H8 completely lost its enzymatic activity within $1 \mathrm{~h}$ of incubation. These results indicated that the lack of in vivo effects of Chil8H8 in B. mori larvae was due to the loss of enzyme activity in the alkaline midgut juice environment, coupled with a probable proteolytic damage caused by the proteases present in the midgut lumen.

\section{DISCUSSION}

In the present work, we tested the insecticidal activity of two recently discovered soil metagenome-sourced chitinases on the larvae of $B$. mori, by using a combined in vivo and in vitro approach. $B$. mori is a model organism among Lepidoptera, which represent the second largest order of insects, including damaging phytophagous species that are still mainly controlled with chemicals. The two chitinases used in this study (Chi18H8 and

TABLE 3 | Effects of Chi18H8 on B. mori growth and development.

\begin{tabular}{lccc}
\hline $\begin{array}{l}\text { Doses of Chi18H8 } \\
\left(\mathbf{U}_{\text {tot }} / \mathbf{c m}^{\mathbf{2}} \mathbf{\text { diet} )}\right.\end{array}$ & $\begin{array}{c}\text { Larval } \\
\text { mortality }(\%)\end{array}$ & $\begin{array}{c}\text { Duration of larval } \\
\text { stage (days) }\end{array}$ & $\begin{array}{c}\text { Pupal weight at } \\
\text { day } \mathbf{8}(\mathbf{g})\end{array}$ \\
\hline $\mathrm{O}$ (control) & $0.00 \pm 0.00$ & $27.21 \pm 0.27$ & $1.32 \pm 0.04$ \\
6 & $6.06 \pm 3.03$ & $27.58 \pm 0.32$ & $1.31 \pm 0.05$ \\
\hline
\end{tabular}

Each value represents the mean \pm standard error of three independent experiments. Each experimental group was composed of 11 larvae. Larvae mortality is reported as the percentage of the initial number of larvae.
53D1) are diverse from all those described previously, possessing specific structural and functional features. Previous results both from sequence and substrate specificity analyses indicated that Chi18H8 belongs to family 18 of glycosyl hydrolases (GH18), showing less than $45 \%$ amino acid sequence identity to any known chitinase (Hjort et al., 2014). Additionally, Chi18H8 possesses an antifungal activity which is uncommon among GH18 chitinases (Hjort et al., 2014; Berini et al., 2017b). This protein seems enough stable to be used in semi-field or field applications, since its range of activity appears adequate for inhibiting fungal phytopathogens growing in acidic and mesophilic environments (Hjort et al., 2014; Berini et al., 2017b). Also 53D1 belongs to GH18 chitinases, showing less than $46 \%$ amino acid sequence identity to any known chitinase. It probably derives from an uncultivable bacterium related to the Chloroflexus species Nitrolancetus hollandicus and Ktedonobacter racemifer (Cretoiu et al., 2015). Although a more complete characterization of 53D1 was hampered by the poor production yield of its recombinant form in E. coli (see below), previous studies showed that this protein tolerates elevated levels of $\mathrm{NaCl}$ : since its activity increases at higher salt levels, 53D1 is considered an uncommon halophilic (rather than halotolerant) chitinase (Cretoiu et al., 2015).

Initially, the major bottleneck to testing insecticidal activity of the two metagenome-sourced chitinases was providing the milligrams needed to perform in vitro and in vivo assay in B. mori. Unfortunately, there is not a highly predictable, all-purpose, and rational protocol to succeed in metagenome-sourced protein expression. Each protein requires the development of its own tailored production process and the selection of the more adequate expression host (Davy et al., 2017). E. coli still remains the first-choice host for protein production, but intrinsic limits of this bacterium are its poor secretory machinery and its tendency 
TABLE 4 | Effects of 53D1 on B. mori growth and development.

\begin{tabular}{|c|c|c|c|c|c|}
\hline $\begin{array}{l}\text { Doses of 53D1 } \\
\left(U_{\text {tot }} / \mathrm{cm}^{2} \text { diet }\right)\end{array}$ & $\begin{array}{c}\text { Larval } \\
\text { mortality (\%) }\end{array}$ & $\begin{array}{l}\text { Duration of larval } \\
\text { stage (days) }\end{array}$ & $\begin{array}{c}\text { Maximal larval weight } \\
\text { before pupation (g) }\end{array}$ & $\begin{array}{l}\text { Pupal weight at } \\
\text { day } 8(\mathrm{~g})\end{array}$ & $\begin{array}{c}\text { Cocoon weight at } \\
\text { day } 8(\mathrm{~g})\end{array}$ \\
\hline 0 (control) & $2.78 \pm 2.78$ & $24.83 \pm 0.21$ & $3.32 \pm 0.09$ & $1.06 \pm 0.04$ & $0.24 \pm 0.01$ \\
\hline 6 & $61.11 \pm 2.78^{*}$ & $31.69 \pm 1.37^{*}$ & $2.14 \pm 0.15^{*}$ & $0.80 \pm 0.06 *$ & $0.13 \pm 0.01 *$ \\
\hline
\end{tabular}

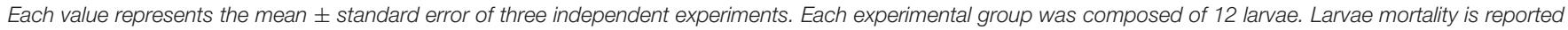
as the percentage of the initial number of larvae. ${ }^{*} p<0.001$ versus control, Student's $t$-test.

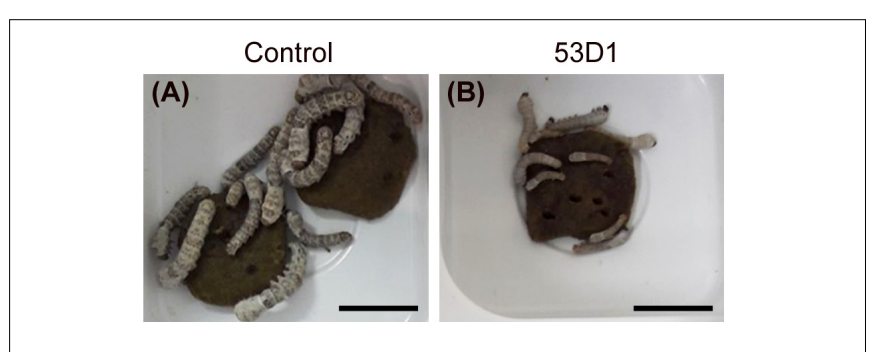

FIGURE 5 | Pictures of $B$. mori larvae, on the 11th day after hatching, reared on artificial diet overlaid with $100 \mathrm{mM}$ sodium acetate, $\mathrm{pH} 5$ (A, control) or 6 $\mathrm{U}_{\text {tot }} / \mathrm{cm}^{2}$ of $53 \mathrm{D} 1$ dissolved in the same buffer $(\mathbf{B})$. All the control larvae are alive and the majority of them have reached the third instar (A); a few larvae treated with the chitinase are already dead, and the majority of the survived larvae are still in the second instar (B). Bars: $1 \mathrm{~cm}$.
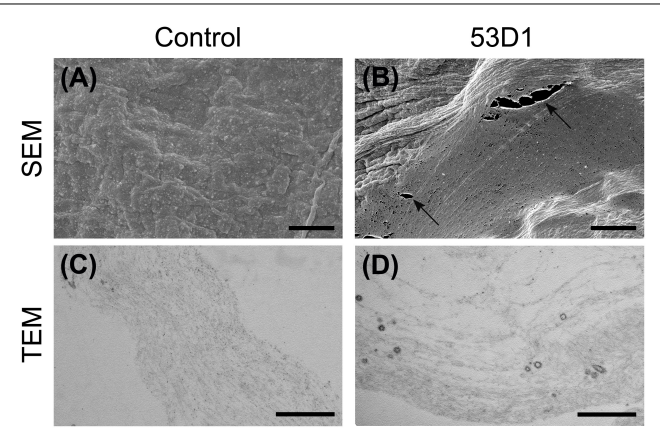

FIGURE 6 | Morphology of the peritrophic matrix isolated from larvae treated with 53D1. SEM (A,B) and TEM (C,D). (A,C) Control samples; (B,D) the treatment with 53D1 determines ruptures of the PM (arrows) and the disruption of the fibril network as confirmed by TEM analysis. Bars: $(\mathbf{A}, \mathbf{B})$ $5 \mu \mathrm{m}$; (C,D) $0.5 \mu \mathrm{m}$.

to accumulate heterologous proteins into IBs, mostly in inactive form. In the case of $\mathrm{Chi} 18 \mathrm{H} 8$, we could recover hundreds of milligrams of pure and active chitinase from processing IBs, following a previously developed and scaled-up process (Berini et al., 2017b), but this approach was not transferable to 53D1 production. In fact, it is widely recognized that the outcome of IB processing is unpredictable and has to be empirically determined for each protein (de Marco et al., 2019; Slouka et al., 2019). After some unsuccessful attempts, 53D1 was finally successfully expressed in S. coelicolor A3(2), although its codon usage was slightly different from the one of streptomycetes $[63 \% \mathrm{G}+\mathrm{C}$ content for $53 \mathrm{D} 1$ gene vs. ca. $72 \%$ for S. coelicolor A3(2) genome] (Kieser et al., 2000). The production level in
S. coelicolor $\mathrm{A} 3(2)$ was satisfactory (around $45 \mathrm{mg} / \mathrm{L}$ ) and the heterologous protein was entirely secreted into the culture broth, thus markedly facilitating its recovery and purification. A single step of affinity chromatography allowed us to recover ca. $35 \mathrm{mg} / \mathrm{L}$ of highly pure protein, with a 60 -fold improvement in volumetric yield when compared to $E$. coli. Streptomycetes, although still relatively poorly explored for the expression of heterologous chitinases, have important advantages versus E. coli. They are non-pathogenic microorganisms, commonly inhabiting soil, where they establish beneficial interactions with plants, by modulating plant defense mechanisms or facilitating symbioses between plant roots and beneficial microbes (Schrey and Tarkka, 2008). Additionally, streptomycetes are already commonly used as components of commercial soil amendments for bioremediation (Sharma et al., 2016; Cuozzo et al., 2018) or biocontrol (González-García et al., 2019; Olanrewaju and Babalola, 2019) and they are generally considered safe for agricultural use. Using this environment-friendly expression system for producing chitinases might represent a further advantage to support their sustainable development as promising insecticide proteins.

Once the supply issue of both proteins was overcome, we decided to test the insecticidal activity of the two pure preparations of Chi18H8 or 53D1 using the $\mathrm{PM}$ of $B$. mori as in vitro and in vivo target. Insects offer two potential targets for chitinases: cuticle, which consists of a pluristratified structure mainly formed by proteins and chitin chains, and PM, where chitin fibrils act as a scaffold for binding glycoproteins and proteoglycans. Both structures exert fundamental roles for the insect survival. Cuticle protects insects from parasites, pathogens, and dangerous chemicals, while allowing muscle attachment and preventing water loss from the body (Moussian, 2010). PM helps in the compartmentalization of digestive processes, protecting the midgut epithelium against abrasive food particles and defending the insect from ingested pathogens (Hegedus et al., 2009). Previous works recently reviewed in Berini et al. (2018) reported that entomopathogenicity of microbial strains is mediated by a cocktail of cuticlehydrolyzing enzymes, which include chitinases. Indeed, the topical insecticide potential of these enzyme combinations is often limited due to the long time required for their action, the need of high local concentrations, and their poor stability and persistence in changing environmental conditions. A more promising perspective seems to be using chitinases for targeting PM via oral ingestion (Berini et al., 2016, 2018). An advantage of this approach is that chitinases might be formulated with other insecticidal molecules, 
A

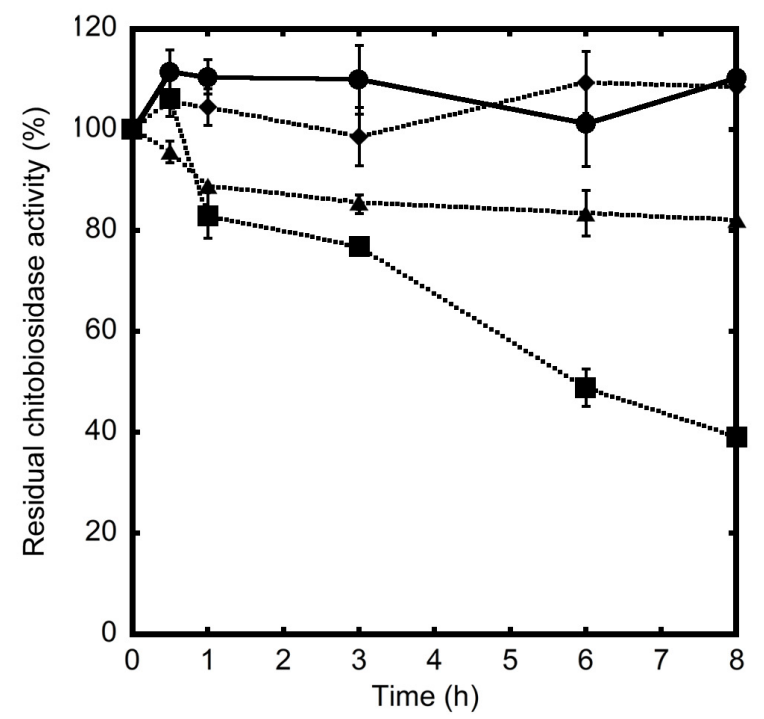

B

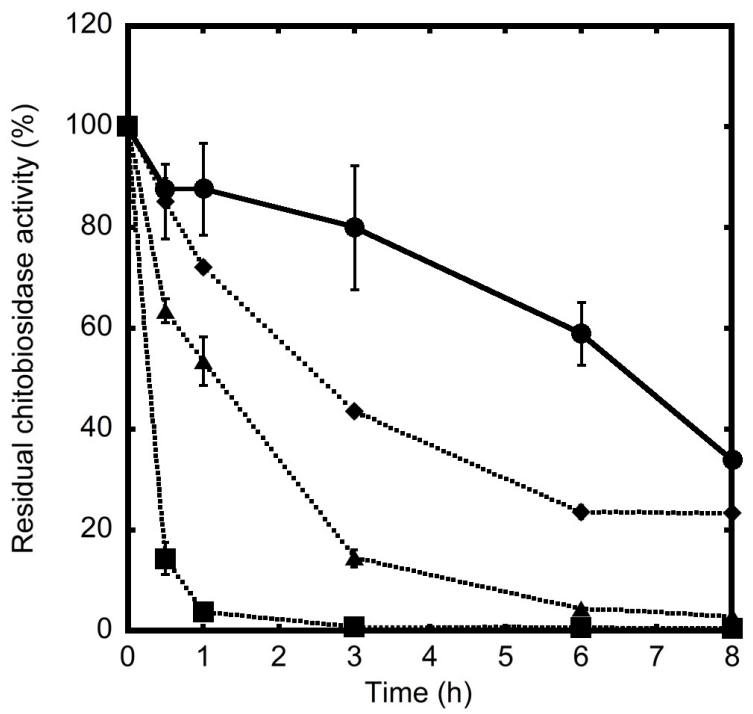

FIGURE 7 | Residual chitinolytic activities of 53D1 (A) and Chi18 $\mathrm{H} 8$ (B), incubated at $25^{\circ} \mathrm{C}$ in Tris- $\mathrm{HCl} \mathrm{pH} 8.0$ (control, $\bullet$, solid line) or in the presence of undiluted

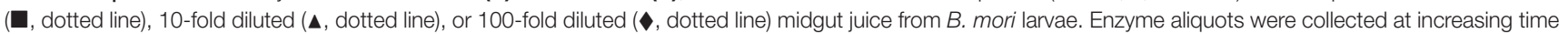
intervals and the residual activity was measured on 4-MU-(GlcNAc) $)_{2}$ as substrate.

facilitating their adsorption/penetration into the midgut epithelium and thus increasing their activity. For instance, the combined oral administration of chitinases with Bacillus thuringiensis $\delta$-endotoxin crystal proteins was reported to dramatically enhance the toxic effect of the latter (Regev et al., 1996; Liu et al., 2010). Additionally, the insecticide activity of TMOF, a peptide that inhibits trypsin synthesis, was increased by combined administration with a viral chitinase (Fiandra et al., 2010).

Our results demonstrated that when the PM of the silkworm was exposed in vitro to chitinases, the combination of endoand exo-activities possessed by both enzymes significantly altered the structure of PM, disrupting the organization of chitin fibrils. Peeling of the superficial layers, ruptures, separation of the fibril networks, and a general weakening of the PM were observed. The effects of the two enzymes were similar, although 53D1 appeared to cause a more marked damage to PM structure. This result was consistent with the demonstrated 53D1 greater activity on colloidal chitin, which mimics the complex insoluble-chitin-containing natural structures. Once orally administered to B. mori larvae, 53D1 induced mortality, enhanced dramatically the duration of the larval stage, and reduced both the maximal larval weight before pupation and pupal and cocoon weight, whereas Chi18H8 did not provoke any consequences on insect development. Ultrastructural analysis of PMs isolated from larvae reared on 53D1-containing diet, showed significant alterations, confirming that the structural damage of this matrix dramatically affected insect development probably due to a reduced nutrient digestion capability. The different in vivo activity between Chi18H8 and 53D1, which might appear puzzling considering that both the enzymes disrupted (although at a different extent) the PM integrity in vitro, became understandable once the poor residual activity of Chi18H8 in the alkaline and proteolytic environment of Lepidoptera midgut lumen was demonstrated. Apparently, the intrinsic properties of 53D1 made this enzyme less susceptible to degradation in the above-mentioned conditions. Although the administration of both chitinases to other insects, especially to those having a midgut lumen with neutral or acidic $\mathrm{pH}$, is worthy to be investigated, this work demonstrates that actually 53D1 can be considered a more promising candidate than Chi18H8 as insecticide protein for oral administration. Fortunately, 53D1 further in vivo and in-field trials will be possible due to the development of a reliable and sustainable production process using as expression platform the unconventional -but more environmentally acceptable-S. coelicolor.

In conclusion, this work shed light on (i) the efficacy of metagenomic investigations for discovering novel enzymes to be implemented as part of integrated pest management programs; (ii) the potential of metagenome-sourced microbial chitinases as promising insecticide proteins; and (iii) the need to develop unconventional heterologous expression platforms to support insecticide protein development and use. Although insecticide formulations based on chemically synthesized compounds still represent a relevant part of crop protection, it is undeniable that insecticide proteins will contribute in future to the progressive reduction of chemicals, introducing novel strategies for managing insect pests. Formulation of chitinases with other biopesticides or chemically synthesized pesticides might allow the reduction of the environmental impact of single toxic compounds and reduce the risk of resistance selection (Chandler et al., 2011; Hardy, 2014). Microbial biotechnology will be crucial to support the development and sustainable production of novel insecticide proteins. 


\section{DATA AVAILABILITY}

All datasets generated for this study are included in the manuscript and/or the supplementary files.

\section{AUTHOR CONTRIBUTIONS}

$\mathrm{FB}, \mathrm{MC}, \mathrm{GT}$, and FM conceived the experiments, interpreted the results, and wrote the manuscript. FB cloned the metagenomesourced genes and produced the metagenome-sourced chitinases. $\mathrm{AM}$ and GT tested the insecticide proteins in vitro. MC tested the insecticide proteins in vivo. MR performed the microscopical observations. FM and GT managed the project. All authors reviewed and approved the final manuscript.

\section{FUNDING}

This research was supported by the MAECI (Ministero degli Affari Esteri e della Cooperazione Internazionale) for the CHITOBIOCONTROL project (Israel-Italy Joint Innovation

\section{REFERENCES}

Adrangi, S., and Faramarzi, M. A. (2013). From bacteria to human: a journey into the world of chitinases. Biotechnol. Adv. 31, 1786-1795. doi: 10.1016/j. biotechadv.2013.09.012

Atwood, D., and Paisley-Jones, C. (2017). Pesticide Industry Sales and Usage 2008-2012 Market Estimates. Washington, DC: United States Environmental Protection Agency.

Berini, F., Caccia, S., Franzetti, E., Congiu, T., Marinelli, F., Casartelli, M., et al. (2016). Effects of Trichoderma viride chitinases on the peritrophic matrix of Lepidoptera. Pest Manag. Sci. 72, 980-989. doi: 10.1002/ps.4078

Berini, F., Katz, C., Gruzdev, N., Casartelli, M., Tettamanti, G., and Marinelli, F. (2018). Microbial and viral chitinases: attractive biopesticides for integrated pest management. Biotechnol. Adv. 36, 818-838. doi: 10.1016/j.biotechadv.2018. 01.002

Berini, F., Casciello, C., Marcone, G. L., and Marinelli, F. (2017a). Metagenomics: novel enzymes from non-culturable microbes. FEMS Microbiol. Lett. 364:fnx211. doi: 10.1093/femsle/fnx211

Berini, F., Presti, I., Beltrametti, F., Pedroli, M., Vårum, K. M., Pollegioni, L., et al. (2017b). Production and characterization of a novel antifungal chitinase identified by functional screening of a suppressive-soil metagenome. Microb. Cell Fact. 16:16. doi: 10.1186/s12934-017-0634-8

Binda, E., Marcone, G. L., Berini, F., Pollegioni, L., and Marinelli, F. (2013). Streptomyces spp. as efficient expression system for a D,D peptidase/D,D-carboxypeptidase involved in glycopeptide antibiotic resistance. BMC Biotechnol. 13:24. doi: 10.1186/1472-6750-13-24

Bokma, E., van Koningsveld, G. A., Jerominus-Stratingh, M., and Beintema, J. J. (1997). Hevamine, a chitinase from the rubber tree Hevea brasiliensis, cleaves peptidoglycan between the C-1 of N-acetylglucosamine and C-4 of $\mathrm{N}$-acetylmuramic acid and therefore is not a lysozyme. FEBS Lett. 411, 161-163. doi: 10.1016/S0014-5793(97)00682-0

Bonanomi, G., Lorito, M., Vinale, F., and Woo, S. L. (2018). Organic amendments, beneficial microbes, and soil microbiota: toward a unified framework for disease suppression. Annu. Rev. Phytopathol. 56, 1-20. doi: 10.1146/annurev-phyto080615-100046

Cappellozza, L., Cappellozza, S., Saviane, A., and Sbrenna, G. (2005). Artificial diet rearing system for the silkworm Bombyx mori (Lepidoptera: Bombycidae): effect of vitamin $\mathrm{C}$ deprivation on larval growth and cocoon production. Appl. Entomol. Zool. 40, 405-412. doi: 10.1303/aez.2005.405
Program for Industrial, Scientific and Technological Cooperation in R\&D, Industrial Track, call 2016). FB received contributions from the Consorzio Italiano per le Biotecnologie (CIB) and Fermentation Journal (MDPI, Basel, Switzerland) for congress participations.

\section{ACKNOWLEDGMENTS}

The authors thank Silvia Cappellozza and Alessio Saviane (CREA-AA, Sericulture Laboratory of Padua, Padua, Italy) for providing Bombyx mori larvae. The authors also acknowledge Sara Sjöling (Södertörn University, Huddinge, Sweden), Jan Dirk Van Elsas (University of Groningen, Groningen, Netherlands), Ilaria Presti (Chemo Biosynthesis, Corana, Pavia, Italy), and Silvia Cretoiu (University of Groningen, Groningen, Netherlands) previous partners in MetaExplore EU-funded project (grant agreement 222625) - for the discovery of the metagenomesourced chitinases. Israeli CHITOBIOCONTROL partners Chen Katz and Uri Marchaim are also acknowledged for collaboration and useful discussions. AM is a Ph.D. student of the "Life Science and Biotechnology" course at the University of Insubria.

Chandler, D., Bailey, A. S., Tatchell, G. M., Davidson, G., Greaves, J., and Grant, W. P. (2011). The development, regulation and use of biopesticides for integrated pest management. Philos. Trans. R. Soc. Lond. Ser. B Biol. Sci. 366, 1987-1998. doi: 10.1098/rstb.2010.0390

Cretoiu, M. S., Berini, F., Kielak, A. M., Marinelli, F., and van Elsas, J. D. (2015). A novel salt-tolerant chitobiosidase discovered by genetic screening of a metagenomic library derived from chitin-amended agricultural soil. Appl. Microbiol. Biotechnol. 99, 8199-8215. doi: 10.1007/s00253-015-6639-5

Cuozzo, S. A., Sineli, P. E., Davila Costa, J., and Tortella, G. (2018). Streptomyces sp. is a powerful biotechnological tool for the biodegradation of $\mathrm{HCH}$ isomers: biochemical and molecular basis. Crit. Rev. Biotechnol. 38, 719-728. doi: 10. 1080/07388551.2017

Czaja, K., Góralczyk, K., Struciński, P., Hernik, A., Korcz, W., Minorczyk, M., et al. (2015). Biopesticides - towards increased consumer safety in the European Union. Pest Manag. Sci. 71, 3-6. doi: 10.1002/ps.3829

Dalmastri, C., Gastaldo, L., Marcone, G. L., Binda, E., Congiu, T., and Marinelli, F. (2016). Classification of Nonomuraea sp. ATCC 39727, an actinomycete that produces the glycopeptide antibiotic A40926, as Nonomuraea gerenzanensis sp. nov. Int. J. Syst. Evol. Microbiol. 66, 912-921. doi: 10.1099/ijsem.0.000810

Damalas, C. A., and Koutroubas, S. D. (2018). Current status and recent developments in biopesticide use. Agriculture 8:13. doi: 10.3390/agriculture 8010013

Davy, A. M., Kildegaard, H. F., and Andersen, M. R. (2017). Cell factory engineering. Cell Syst. 4, 262-275. doi: 10.1016/j.cels.2017.02.010

de Marco, A., Ferrer-Miralles, N., Garcia-Fruitós, E., Mitraki, A., Peternel, S., Rinas, U., et al. (2019). Bacterial inclusion bodies are industrially exploitable amyloids. FEMS Microbiol. Rev. 43, 53-72. doi: 10.1093/femsre/fuy038

Fiandra, L., Terracciano, I., Fanti, P., Garonna, A., Ferracane, L., Fogliano, V., et al. (2010). A viral chitinase enhances oral activity of TMOF. Insect Biochem. Mol. Biol. 40, 533-540. doi: 10.1016/j.ibmb.2010.05.001

Franzetti, E., Huang, Z. J., Shi, Y. X., Xie, K., Deng, X. J., Li, J. P., et al. (2012). Autophagy precedes apoptosis during the remodeling of silkworm larval midgut. Apoptosis 17, 305-324. doi: 10.1007/s10495-011-0675-0

González-García, S., Alvarez-Pérez, J. M., Sáenz de Miera, L. E., Cobos, R., Ibañez, A., Díez-Galán, et al. (2019). Developing tools for evaluating inoculation methods of biocontrol Streptomyces sp. strains into grapevine plants. PLoS One 14:e0211225. doi: 10.1371/journal.pone.0211225

Hardy, M. C. (2014). Resistance is not futile: it shapes insecticide discovery. Insects 5, 227-242. doi: 10.3390/insects5010227 
Hegedus, D., Erlandson, M., Gillott, C., and Toprak, U. (2009). New insights into peritrophic matrix synthesis, architecture and function. Annu. Rev. Entomol. 54, 285-302. doi: 10.1146/annurev.ento.54.110807.090559

Hjort, K., Presti, I., Elväng, A., Marinelli, F., and Sjöling, S. (2014). Bacterial chitinase with phytopathogen control capacity from suppressive soil revealed by functional metagenomics. Appl. Microbiol. Biotechnol. 98, 2819-2828. doi: 10.1007/s00253-013-5287-x

Hobbs, G., Frazer, C. M., Gardner, D. C. J., Cullum, J. A., and Oliver, S. G. (1989). Dispersed growth of Streptomyces in liquid culture. Appl. Microbiol. Biotechnol. 31, 272-277. doi: 10.1007/BF00258408

Karasuda, S., Tanaka, S., Kajihara, H., Yamamoto, Y., and Koga, D. (2003). Plant chitinase as a possible biocontrol agent for use instead of chemical fungicides. Biosci. Biotechnol. Biochem. 67, 221-224. doi: 10.1271/bbb.67.221

Kieser, T., Bibb, M. J., Buttner, M. J., Chater, K. F., and Hopwood, D. A. (2000). Practical Streptomyces Genetics. Norwich: John Innes Foundation.

Kumar, S., Nehra, M., Dilbaghi, N., Marrazza, G., Hassan, A. A., and Kim, K. H. (2019). Nano-based smart pesticide formulations: emerging opportunities for agriculture. J. Control Release 294, 131-153. doi: 10.1016/j.jconrel.2018.12.012

Liu, D., Cai, J., Xie, C. C., Lium, C., and Chen, Y. H. (2010). Purification and partial characterization of a $36-\mathrm{kDa}$ chitinase from Bacillus thuringiensis subsp. colmeri and its biocontrol potential. Enzym. Microb. Technol. 46, 252-256. doi: 10.1016/j.enzmictec.2009.10.007

Marcone, G. L., Carrano, L., Marinelli, F., and Beltrametti, F. (2010a). Protoplast preparation and reversion to the normal filamentous growth in antibioticproducing uncommon actinomycetes. J. Antibiot. 63, 83-88. doi: 10.1038/ja. 2009.127

Marcone, G. L., Foulston, L., Binda, E., Marinelli, F., Bibb, M. J., and Beltrametti, F. (2010b). Methods for the genetic manipulation of Nonomuraea sp. ATCC 39727. J. Ind. Microbiol. Biotechnol. 37, 1097-1103. doi: 10.1007/s10295-0100807-805

Mavromatis, K., Lorito, M., Woo, S. L., and Bouriotis, V. (2003). Mode of action and antifungal properties of two cold-adapted chitinases. Extremophiles 7, 385-390. doi: 10.1007/s00792-003-0338-3

Moussian, B. (2010). Recent advances in understanding mechanisms of insect cuticle differentiation. Insect Biochem. Mol. Biol. 40, 363-375. doi: 10.1016/j. ibmb.2010.03.003

Neeraja, C., Anil, K., Purushotham, P., Suma, K., Sarma, P., Moerschbacher, B. M., et al. (2010). Biotechnological approaches to develop bacterial chitinases as a bioshield against fungal diseases of plants. Crit. Rev. Biotechnol. 30, 231-241. doi: $10.3109 / 07388551.2010 .487258$
Olanrewaju, O. S., and Babalola, O. O. (2019). Streptomyces: implications and interactions in plant growth promotion. Appl. Microbiol. Biotechnol. 103, 11791188. doi: 10.1007/s00253-018-09577-y

Regev, A., Keller, M., Strizhov, N., Sneh, B., Prudovsky, E., Chet, I., et al. (1996). Synergistic activity of a Bacillus thuringiensis delta-endotoxin and a bacterial endochitinase against Spodoptera littoralis larvae. Appl. Environ. Microbiol. 62, 3581-3586.

Schrey, S. D., and Tarkka, M. T. (2008). Friend and foes: streptomycetes as modulators of plant disease and symbiosis. Antonie Van Leeuwenhoek 94, 11-19. doi: 10.1007/s10482-008-9241-3

Sharma, A., Singh, S. B., Sharma, R., Chadhary, P., Pandey, A. K., Ansari, R., et al. (2016). Enhanced biodegradation of PAHs by microbial consortium with different amendment and their fate in in-situ condition. J. Environ. Manage. 181, 728-736. doi: 10.1016/j.jenvman.2016.08.024

Slouka, C., Kopp, J., Spadiut, O., and Herwig, C. (2019). Perspectives of inclusion bodies for bio-based products: curse or blessing? Appl. Microbiol. Biotechnol. 103, 1143-1153. doi: 10.007/s00253-018-9569-1

Soares, F. E. D. F., Queiroz, J. H. D., Araújo, J. V. D., Queiroz, P. V., Gouveia, A. D. S., Hiura, E., et al. (2015). Nematicidal action of chitinases produced by the fungus Monacrosporium thaumasium under laboratorial conditions. Biocontrol Sci. Techn. 25, 1-17. doi: 10.1080/09583157.2014.979133

Terra, W. R., and Ferreira, C. (1994). Insect digestive enzymes: properties, compartmentalization and function. Comp. Biochem. Physiol. 109, 1-62. doi: 10.1016/0305-0491(94)90141-4

Wohlkönig, A., Huet, J., Looze, Y., and Wintjens, R. (2010). Structural relationship in the lysozyme superfamily: significant evidence for glycoside hydrolase signature motifs. PLoS One 5:e15388. doi: 10.1371/journal.pone.001 5388

Conflict of Interest Statement: The authors declare that the research was conducted in the absence of any commercial or financial relationships that could be construed as a potential conflict of interest.

Copyright (C) 2019 Berini, Casartelli, Montali, Reguzzoni, Tettamanti and Marinelli. This is an open-access article distributed under the terms of the Creative Commons Attribution License (CC BY). The use, distribution or reproduction in other forums is permitted, provided the original author(s) and the copyright owner(s) are credited and that the original publication in this journal is cited, in accordance with accepted academic practice. No use, distribution or reproduction is permitted which does not comply with these terms. 